Supplementary materials for

\title{
Size-Tunable Continuous Seed-Mediated Growth of Silver Nanoparticles in Alkylamine Mixture via the Stepwise Thermal Decomposition of Silver Oxalate
}

Takanari Togashi*, Koki Tsuchida, Shiori Soma, Ryosuke Nozawa, Jun Matsui, Katsuhiko Kanaizuka, and Masato Kurihara*

Faculty of Science, Yamagata University, 1-4-12- Kojirakawa-machi, Yamagata 990-8560, Japan

\section{Contents:}

Figure S1. Experimental setup for the synthesis of Ag NPs.

Figure S2. Lower magnification TEM images of the Ag NPs synthesized via stepwise thermal decomposition with (a) 0 , (b) 0.5 , (c) 1.0 , (d) 2.0, (e) 3.0, and (f) 4.0 of added $\mathrm{Ag}_{2}(\mathrm{ox})$.

Figure S3. Size distribution of the Ag NPs synthesized via stepwise thermal decomposition with (a) 0 , (b) 0.5 , (c) 1.0 , (d) 2.0, (e) 3.0, and (f) 4.0 of added $\mathrm{Ag}_{2}$ (ox).

Figure S4. TEM images of Ag NPs synthesized by one-pot thermal decomposition of (a) 0.7 , (b) $1.2 \mathrm{~g}$, (c) $2.2 \mathrm{~g}$, (d) $3.2 \mathrm{~g}$, and (e) $4.2 \mathrm{~g}$ of $\mathrm{Ag}_{2}(\mathrm{ox})$.

Figure S5. SEM image of the Ag NPs synthesized via stepwise thermal decomposition with $4.0 \mathrm{~g}$ of added $\mathrm{Ag}_{2}(\mathrm{Ox})$.

Figure S6. Size distribution of the Ag NPs synthesized via stepwise thermal decomposition of (a) $0.22 \mathrm{~g}$, (b) $0.33 \mathrm{~g}$, (c) 0.47 , (d) 0.64 , (e) 0.85 , (f) 1.10 , (g) 1.40 , and (h) $1.75 \mathrm{~g}$ of $\mathrm{Ag}_{2}(\mathrm{ox})$.

Figure S7. LSPR peak position ( $\left.\lambda_{\max }\right)$ of Ag NPs films vs. diameter of Ag NPs. 


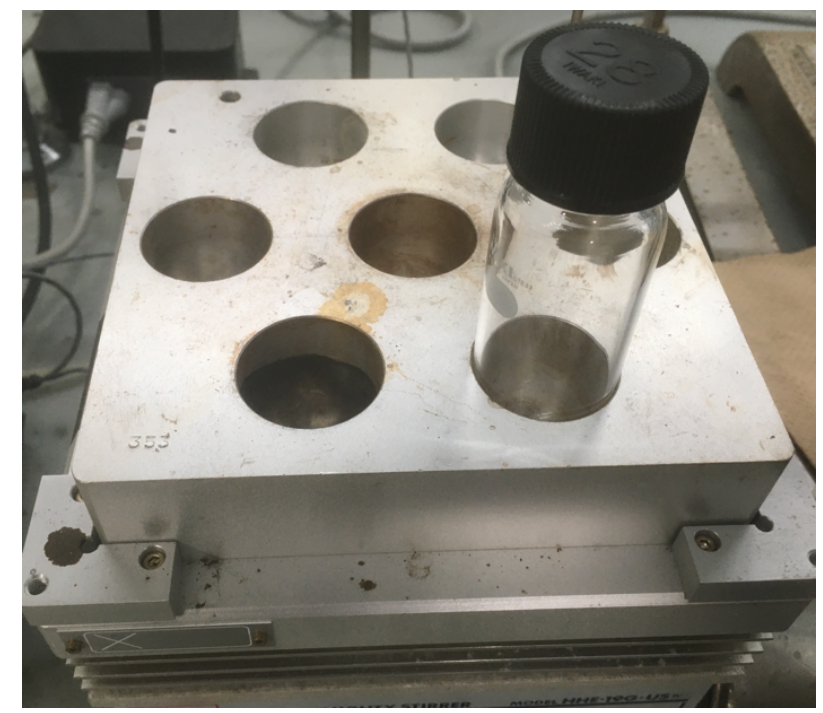

Figure S1. Experimental setup for the synthesis of Ag NPs.
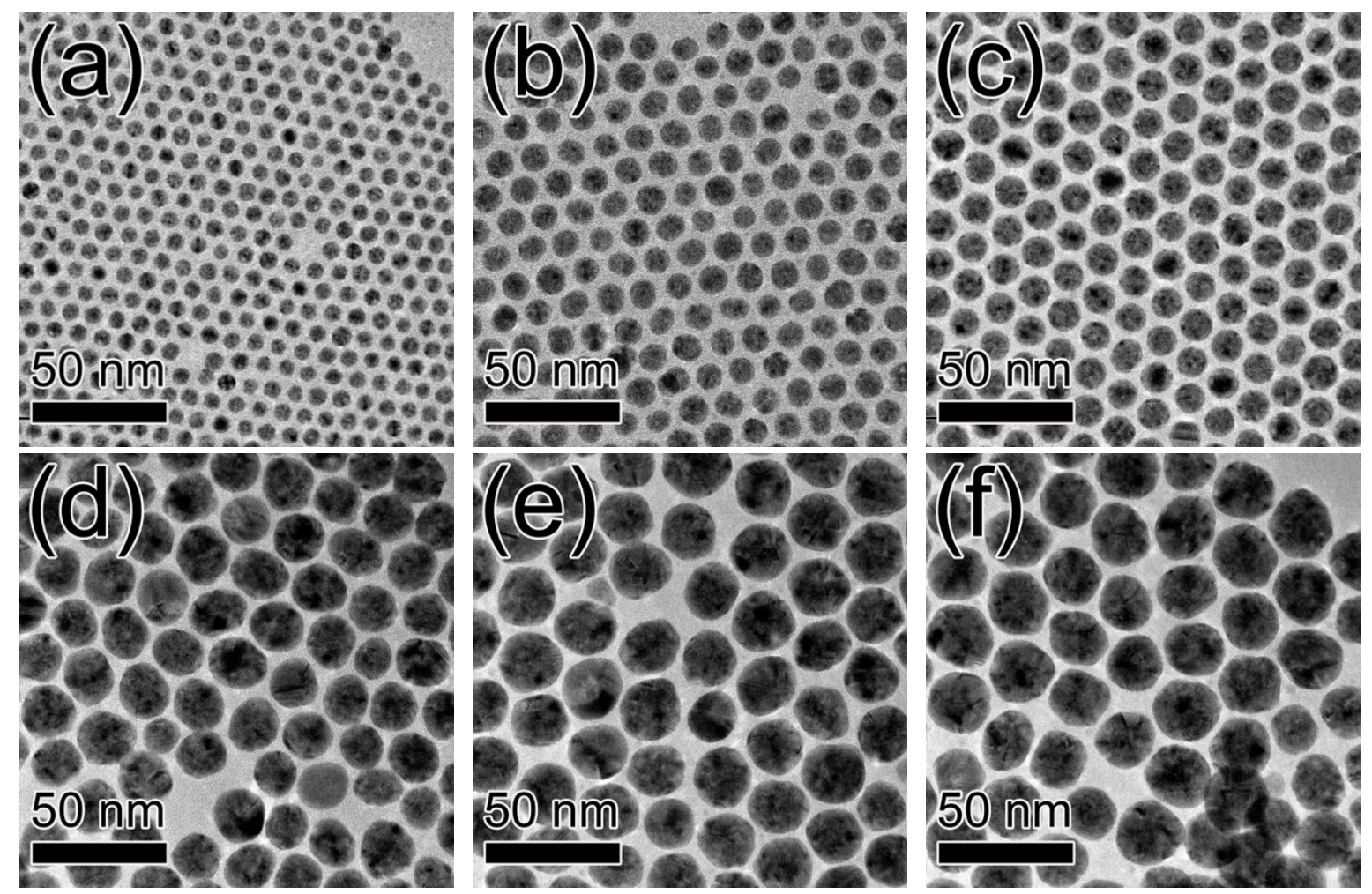

Figure S2. Lower magnification TEM images of the Ag NPs synthesized via stepwise thermal decomposition with (a) 0, (b) 0.5 , (c) 1.0 , (d) 2.0, (e) 3.0, and (f) 4.0 of added $\mathrm{Ag}_{2}(\mathrm{ox})$. 

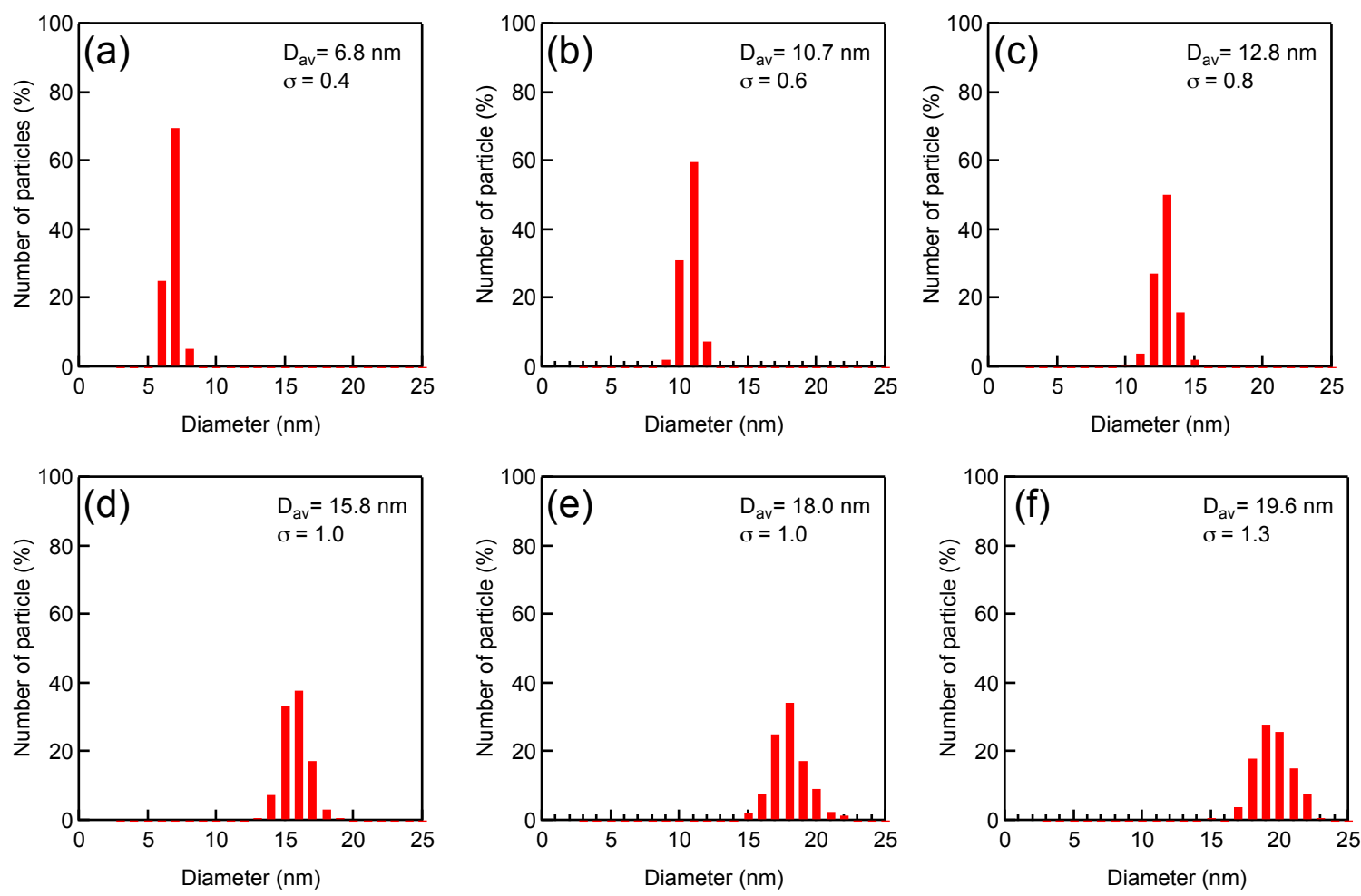

Figure S3. Size distribution of the Ag NPs synthesized via stepwise thermal decomposition with (a) 0, (b) 0.5, (c) 1.0, (d) 2.0, (e) 3.0, and (f) 4.0 of added $\mathrm{Ag}_{2}(\mathrm{ox})$. 

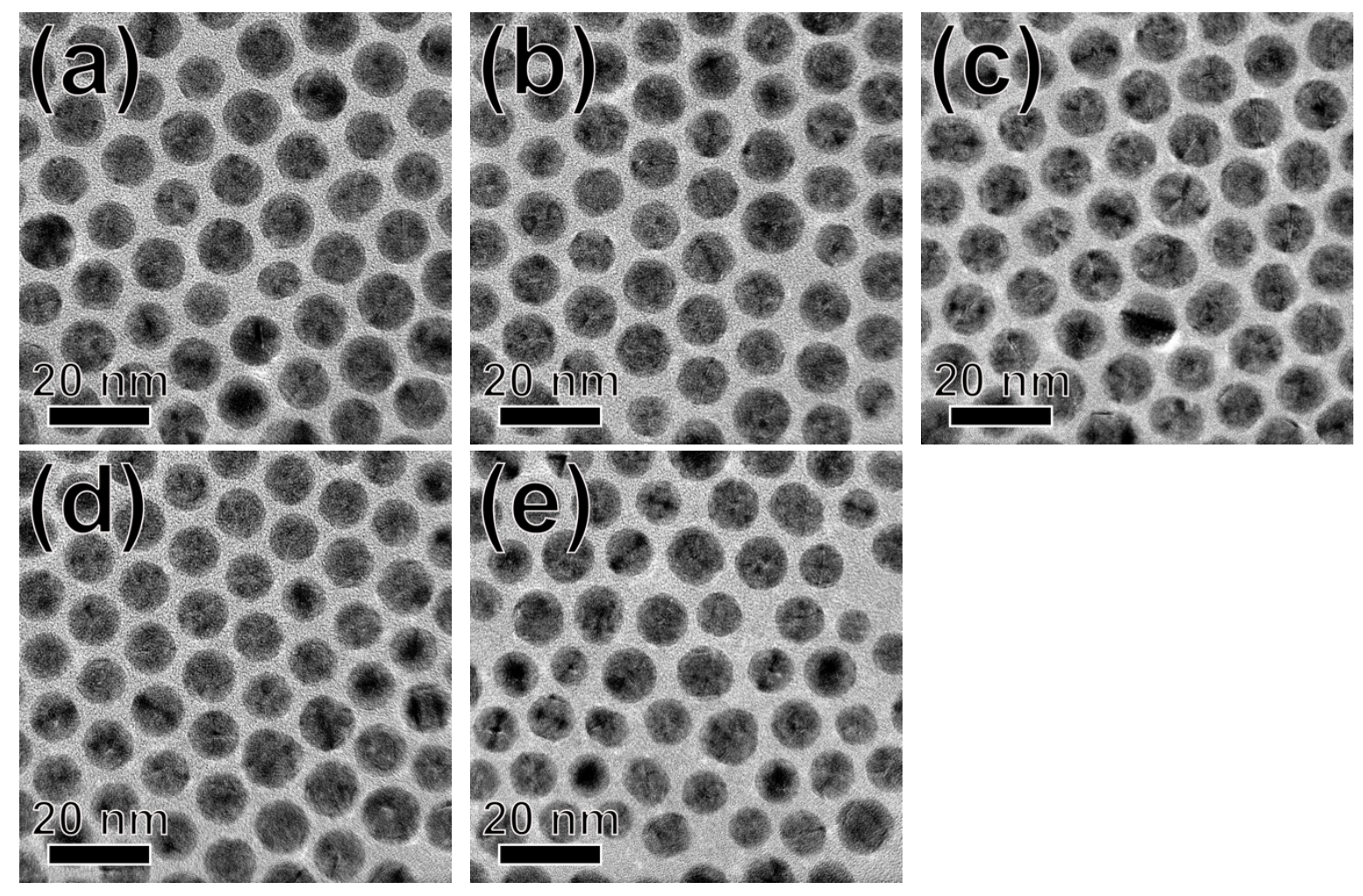

Figure S4. TEM images of Ag NPs synthesized by one-pot thermal decomposition of (a) 0.7 ,

(b) $1.2 \mathrm{~g}$, (c) $2.2 \mathrm{~g}$, (d) $3.2 \mathrm{~g}$, and (e) $4.2 \mathrm{~g}$ of $\mathrm{Ag}_{2}(\mathrm{ox})$.

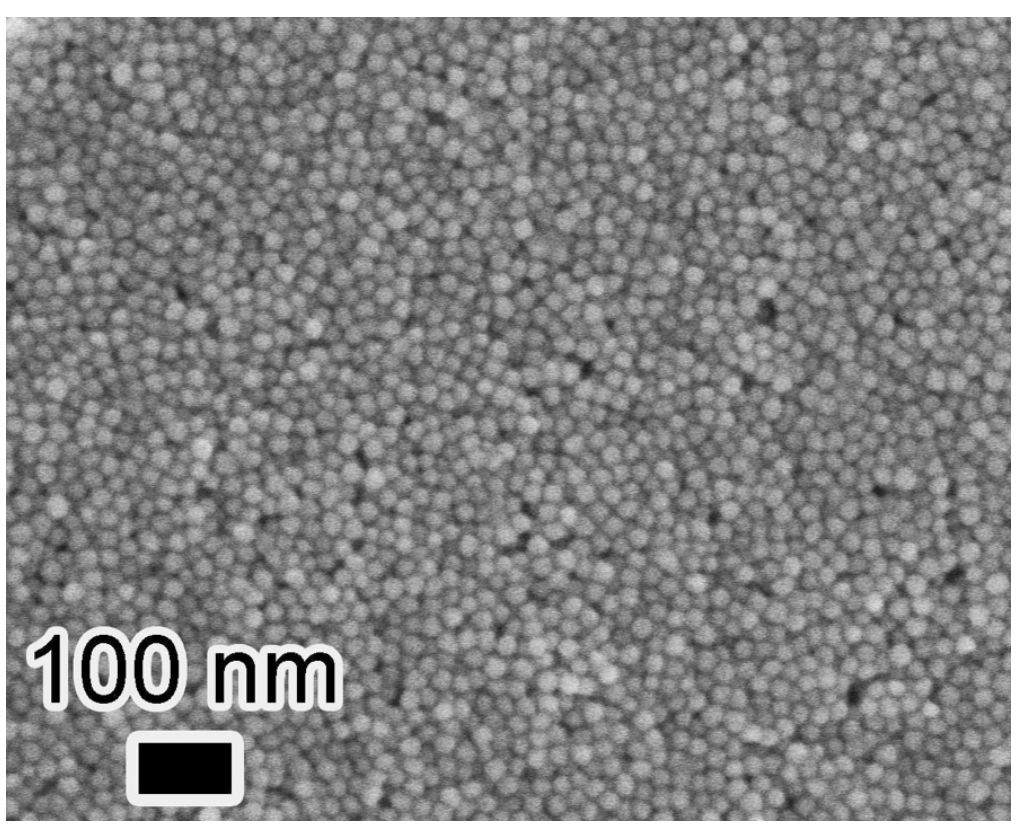

Figure S5. SEM image of the Ag NPs synthesized via stepwise thermal decomposition with $4.0 \mathrm{~g}$ of added $\mathrm{Ag}_{2}(\mathrm{ox})$. 

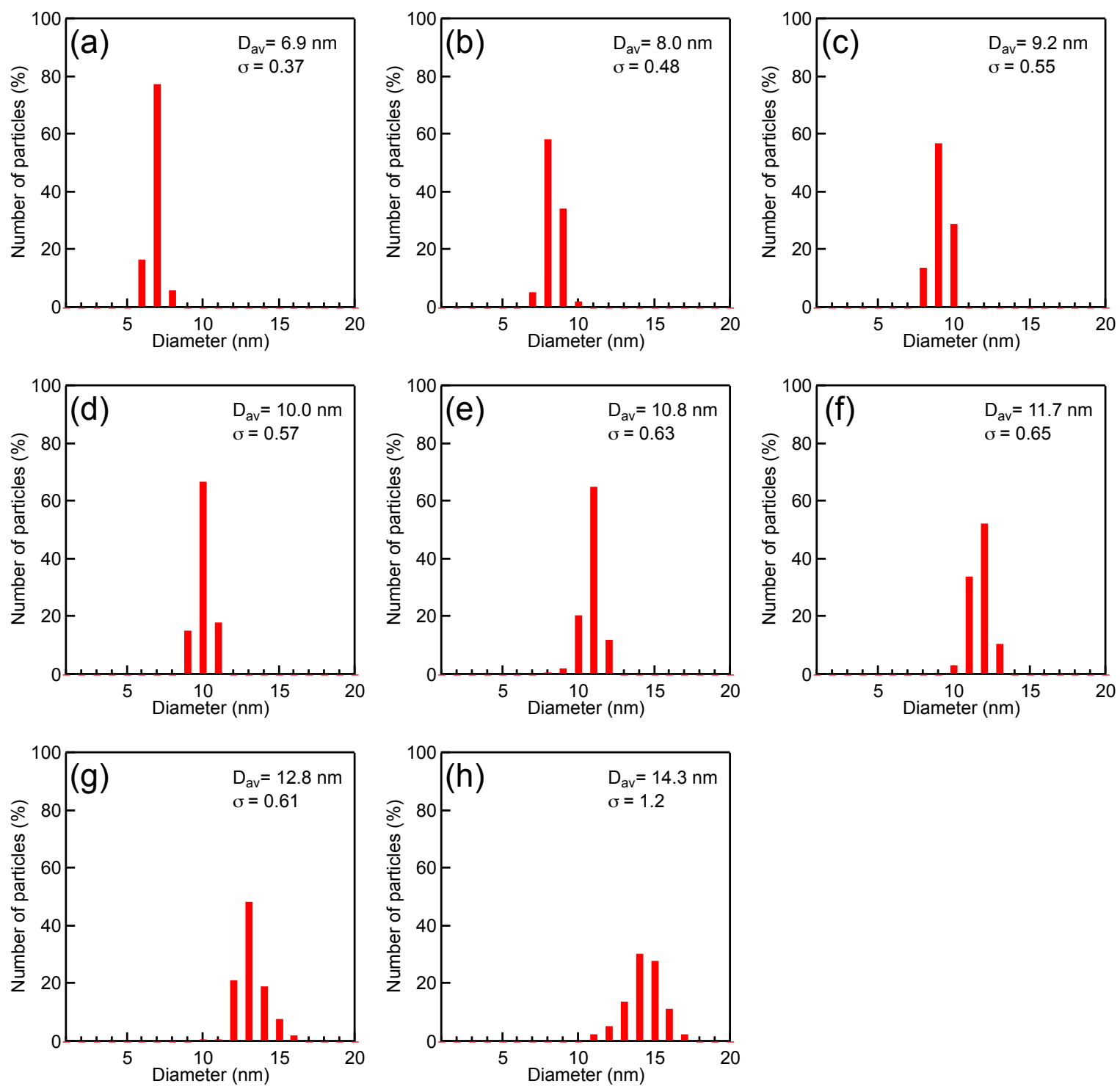

Figure S6. Size distribution of the Ag NPs synthesized via stepwise thermal decomposition of (a) $0.22 \mathrm{~g}$, (b) $0.33 \mathrm{~g}$, (c) 0.47 , (d) 0.64 , (e) 0.85 , (f) 1.10 , (g) 1.40 , and (h) $1.75 \mathrm{~g}$ of $\mathrm{Ag}_{2}(\mathrm{ox})$. 


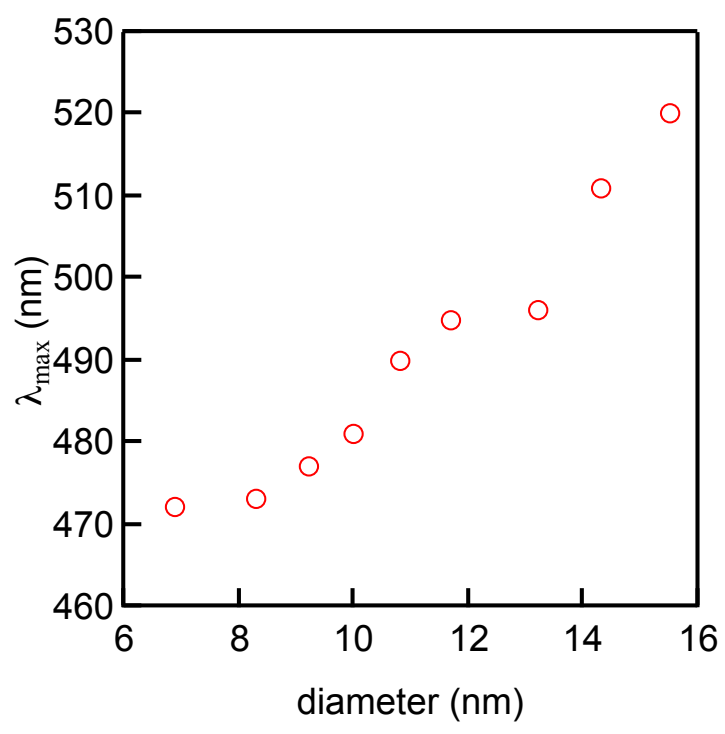

Figure S7. LSPR peak position ( $\lambda_{\max }$ ) of Ag NPs films vs. diameter of Ag NPs. 